\title{
Students' Argumentation for Solving Geometry in Junior High School
}

\author{
Arista Nur Jannah AR \\ ${ }^{1}$ Mathematics Education Program, Postgraduate \\ Program, Universitas Negeri Surabaya, Ketintang St., \\ Surabaya 60231, Indonesia \\ aristaar16070785048@mhs.unesa.ac.id
}

\author{
Dwi Juniati, Raden Sulaiman \\ Department of Mathematics Education, Universitas \\ Negeri Surabaya, Ketintang St. Surabaya 60231, \\ Indonesia
}

\begin{abstract}
Mathematics learning requires students to be active in learning. Mathematical learning should also encourage students to express mathematical ideas according to what they have learned. Students must be able to unfold their argumentation while solving problems. This study aims to investigate the ability of students' mathematical argumentation related to solving geometry. Two volunteer students of the junior high school in $2^{\text {nd }}$ grade who have the same ability were chosen as research subjects. Selected students were given tests related to the geometry problem. The results of the test were analyzed and semi-structured interviews were conducted on the two students. From the test, it was found that students cannot apply their argumentations into writing. This is because they do not know the steps to apply the argumentation in solving the problem. During the interview, students can be responsible for what they write. This means they can argue verbally so as to not to have difficulty in solving problems related to geometry. From the results of this study students should be taught about the procedure of argumentation in mathematics, so that the problem can be solved properly and correctly.
\end{abstract}

Keywords- Argumentation, Geometry, Math Problem, Problem Solving.

\section{INTRODUCTION}

Research conducted by Forman, Joerns, Stein, and Brown [1] found that students achieve learning goals when learning takes place by which students are able to frame mathematical content from lessons in facts or reasons, algorithms or warrants, premises or backing, and claim. Those are the components in the argument. So, student has a good mathematical argument ability, but teachers are not aware of it. CCSSM states that the mathematical argumentation is one of eight practices across values and all mathematical topics [2]. Mathematical argumentation is also a special type of discourse, the purpose of which is to determine the correctness of mathematical statements [3]. Thus, the argumentation is important to be taught in mathematics learning.

The argumentation by Toulmin [4] is a statement used to convince people that conclusions are acceptable. Students should be given an opportunity to express their arguments according to their knowledge, not from imitating what the teacher does. The arguments of these students will make students understand math correctly. So that students 'understanding can be known from students' argumentation either in writing or orally.

Reasons for argumentation will be useful when students solve math problems. In math problem solving, there are steps that contain the reasons for the solution being correct. The reason is the argumentation put forward by students to reach the right solution. As Anderson [5] says that in solving mathematical problems it is better to understand it than to just take the basic arithmetic facts. The argumentation process can be seen when students solve math problems. Mathematical problems are questions in mathematics that require mathematical knowledge and ability to accomplish.

According to Polya [6] solving math problems requires four steps: understanding the problem, planning the completion, implementing the plan, and looking back. Student mathematical argument will be used when problem solving. When students plan and complete a plan, students need a component of data argumentation, warrants, and backing. So by solving mathematical problems, students also need an appropriate argument to strengthen the answer

\section{REVIEW OF LITERATURE}

\section{A. Argumentation}

Argument and argumentation are different terms, argumentation is a dialogical process in which two or more persons are involved in the debate against the claim [7]. While the argument as a product of a person in building a claim.

In mathematics learning, argumentation also emerges as a key feature, although in different ways. With regard to mathematics learning, one usually assumes that participation in argumentation, which seems rather explicit and sophisticated, is a prerequisite for learning possibility, not just desirable out [8]. Argumentation is a discourse that needs to be explicitly taught, through the provision of appropriate activity, support, and modeling [9]. Then the argument is also important for education in school. So the teacher should guide 
the students to make learning that is exposed to the element of argumentation.

Argumentation is the process of collecting the various information needed to support the claim [9]. Claims are the same as solutions in solving problems. To achieve the solution, students must go through several stages that must be clear how these stages can be considered true. So the question would be true.

Arguments refer to the substance of claim, data, warrant, and backing that contribute to the content of the argument, whereas argumentation refers to the assembly process of these components [9]. Component argumentation Toulmin there are 6 that is claim, data, warrant, qualifier, backings, and rebuttals [4].

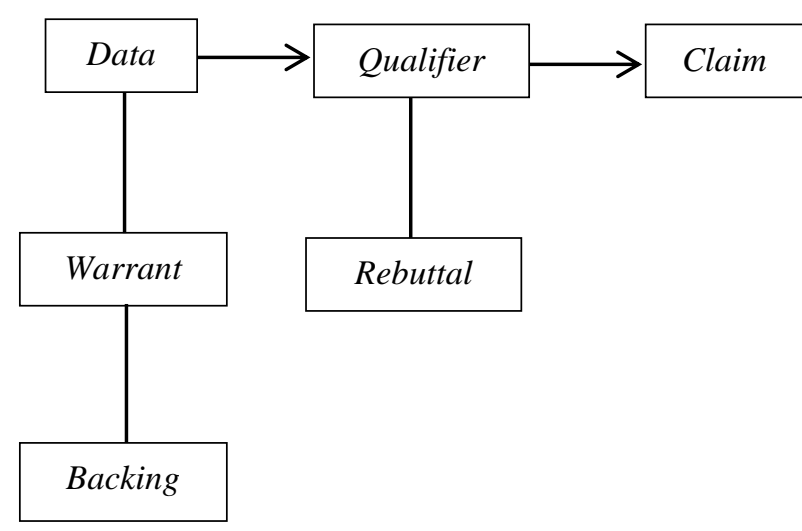

Figure1: Component argument by Toulmin

The argumentation by Toulmin [4] is a statement used to convince people that conclusions are acceptable. Six element by Toulmin are Claims is an affirmation of what exists or values people hold [9]. Claim is a statement that requires argumentative support, either explicitly or implicitly [3].

Claim is also a statement put forward by the argumentator to establish the accepted truth [10]. In learning in math classes, students can provide different solutions to problems that are competing claims [3].

Data is a fact that is proposed to support the claim. Or statement used as evidence to support claim [9;11]. In learning math facts that exist in the matter is data that will support the claim.

Warrant is a remark that explains why certain reasons are relevant to the claim [3]. Warrant is also a rule, principle, and others. Warrant can be called a statement that explains the data relationship with claim [11]. In a discussion in a mathematics class, a warrant may be a formula or an algorithm that allows us to find the value of an unknown variable of a known variable value [4].
Backings is a phrase that reinforces the acceptance of the warrant so that the relationship between data and claim is not examined further. In a sense, backing is a framework in which the warrant is retained as a valid conclusion [8;11]. Backing can also be said to support the warrant.

Qualifiers are argumentative components that explain the power of warrants, such as 'necessarily' or 'maybe' [12]. Qualifiers also can dkatakan special conditions where the claim is valid. This determines the conditions under which claims can be properly represented the limitations of claims [11].

Rebuttals is a condition when a claim is considered incorrect. Statements that are contrary to data, evidence, support or warrant [11].

\section{B. Problem Solving}

Mathematical problems mean questions or situations related to mathematics that are so varied that it requires the right method and mathematical knowledge to be solved. [13]. Activate and train new ways of thinking and expand existing skills, be able to open new mathematical views or give new light to existing objects, structures and mathematical processes [14]. While the problem solving is the process of thinking in solving the problem. State that mathematical problem solving is the process of thinking in which a solver tries to understand the problem situation by using mathematical knowledge that he possesses and tries to gain new information about the situation until he can "resolve tension or ambiguity "[15].

As for Polya [6] in solving the problem there are several stages that is: (1) Understanding the problem, how to understand the problem is to read carefully the existing math problem. (2) Devising a plan, planning for problem solving is not easy, students are required to find ideas to plan for problem solving. (3) Carrying out the plan, This stage students solve the problem according to what has been planned before. (4) Looking back, At this stage students make corrections to their work.

\section{Purpose of the Study}

The purpose of the study is to answer how the mathematical argumentation of students when solving geometry problems.

\section{METHOD}

This study is based on data collection and is described as being in accordance with the findings in the field. This study has a purpose to find out how the ability of students' mathematical argument while doing mathematical problems This research was conducted to two students in the same class in junior high school. The two students have the same abilities. The data obtained comes from test arguments and 
interviews based on tests. The data obtained were analyzed and presented qualitatively.

\section{RESULTS}

The formant component is visible when students are working on written questions as well as during interviews. The research findings are as follows:

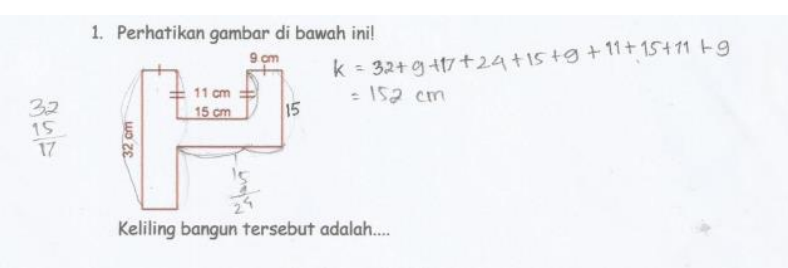

Figure 2: Mathematical argumentation of student 1

In the first steps in Polya's pattern, which is understanding the problem, the student first applies it by reading the question and understanding what he will do next. At the understanding the problem stage students do not write it on the answer sheet. At this stage students should be able to find the data argumentation component, but the first student does not write it on the answer sheet. In the second stage, namely devising a plan, students also do not write it on the answer sheet. Even though students should be able to write down the components of the backing and warrat argumentation. In the next step of the pattern, namely carrying out the plan, students first do the plan and write it on the answer sheet. At this stage students write their claim. The last pattern of the pattern is looking back, the student corrects the calculation again whether there is an error in counting.

The student answer sheet does not show the argument. But explicitly the argument component is visible when doing a write test.

When the student interview also raises the argumentation component of the first student interview on the first problem is:

Teacher : How did you do this?

Student 1 : This is the question of searching for perimeter of the plane

Teacher : How to search perimeter of the plane?

Student 1 : By summing the sides of the plane

Teacher : How are you looking for the unknown side?

Student 1 : By looking for the other side of the same length

Teacher : What conclusions do you get from this problem?

Student 1 : The perimeter of the plane is $152 \mathrm{~cm}$

This means students understand the concept of traveling, so that students meet warrant argument components. When responding that the perimeter plane is $152 \mathrm{~cm}$. This means students know about the solution or claim. Students also meet the data and backing components during the interview.

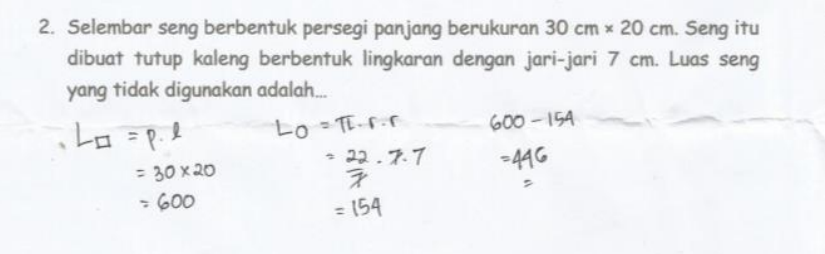

Figure 3: Mathematical argumentation of student 1

On the second problem first students are able to describe the answers in writing. By writing the Area formula, students meet the backing component, as it supports the existence of warant. Warant of the student's writing is the multiplication of the area of the rectangle and the circle. Students also write down the claim but not with detailed writing. But when teachers interview students, students know what the claim of the problem. So students can mention the components of argument warrants, backing, claim and data on oral argumentation. But in the argument write students do not mention data from the problem.

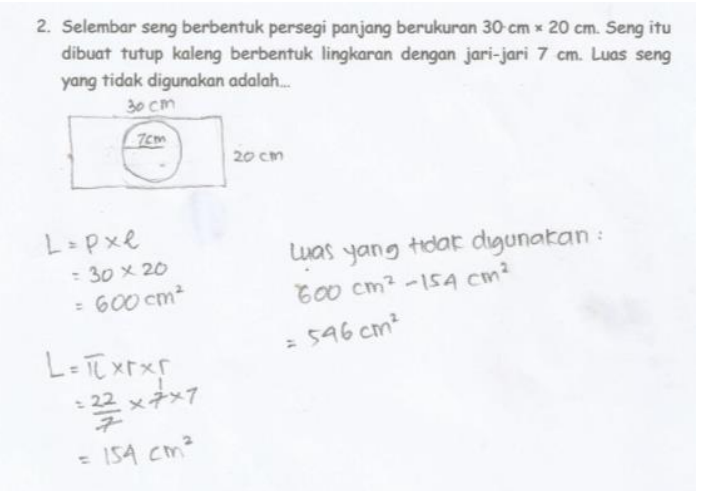

Figure 4: Mathematical argumentation of student 2

The second student has almost the same argument on the first question. The second student also contains data components, warrants, backing, and claim explicitly. The second student also gave the appropriate argument during the interview. This means that the second student also has a good oral and written argument on the first question. so the second student is able to solve the problem well

The work is quite different on the matter number two, student 2 reaffirms the component data on his argument by way of visualizing math problems with images. Student 2 adds his argumentation by understanding the problem in greater depth. During the interview students also argued well. Data components, warrants, backing, and claim are also well explained. so the second student also solves the problem correctly 


\section{CONCLUSION}

Students have a pretty good argument in solving math problems. Student arguments explicitly arise when solving write problems. Not only that students are also able to argue verbally. This is evident when students are asked the reasons why they answer like that, they can answer fluently. So the argument is also important taught to students so that students can solve math problems well. Not just imitating what the teacher conveyed.

Student argument while doing mathematics problem consist of data component, backing, warrant, and claim. In this study did not appear rebuttal and qualifier. Rebuttal does not appear because the problem used is not a matter of proof. Qualifiers do not appear because sometimes in solving the qualifier problem is not so important. In learning, teachers should be able to direct students to the 6 components of Toulmin's argument. From the results of this study should the students be studying the procedure of argument in mathematics, so that in solving the problem can be solved properly and correctly.

In solving the problem, if you want to generate rebuttal component then use "problem to prove" instead of using "problem to find". Problem to prove is widely used when solving flat wake problems such as congruence. In further research it might be possible to examine the "problem to prove".

\section{REFERENCES}

[1] A. F. Ellice, L. J. Jorge, M. K. Stein, and C. A. Brown, "You're going to want to find out which and prove it: Collective argumentation in a mathematics classroom", Learning and Instruction, vol. 8, no.6, pp. 527$548,1998$.

[2] Common Core State Standards Initiative (CCSSI), Common Core State Standards for Mathematics, Washington, DC: National Governors
Association Center for Best Practices and the Council of Chief State School Officers, 2010

[3] J. Knudsen, T. Meloy, Stevens, S. Harriette, and Rutstein, Mathematical argumentation in Middle School, (The National Council of Teachers of Mathematics, Inc. www.nctm.org), 2014, p. 2.

[4] S. Toulmin, The uses of argument: Updated edition, University of Southern California : Cambridge University Press, 2003, pp. 1-247.

[5] J. R. Anderson, H. S. Lee, J. M. Finchama, "Discovering the structure of mathematical problem solving", NeuroImage, vol. 97, pp. 163-177, 2014.

[6] G. Polya, How to Solve It: A New Aspect of Mathematical Method, United States of America: British Library Cataloging, 2014.

[7] D. Kuhn and W. Udell, "The Development of Argument Skills", Child Development, vol. 74, no. 5, pp. 1245-1260, 2003.

[8] G. Krummheuer, "Argumentation and participation in the primary mathematics classroom. Two episodes and related theoretical abductions", Journal of Mathematical Behavior, vol. 26, no. 1, pp. 60 $82,2007$.

[9] S. Simon, S. Erduran, and J. Osborne, "Learning to teach argumentation: Research and development in the science classroom", International Journal of Science Education, vol. 28, no. 2-3, pp. 235-260, 2006.

[10] K. W. Kosko, "Making use of what's given: Children's detailing inmathematical argumentative writing", The Journal of Mathematical Behavior, vol. 41, no. 68-86, p. 3, 2016.

[11] R. Driver, P. Newton, and J. Osborne, "Establishing The Norms of Scientific Argumentation in Classrooms", Science Education, vol. 88, no. 6, p. $287,1998$.

[12] A. Aberdein, "The Uses of Argument in Mathematics", Springer, vol. 19, pp. 287-301, 2005.

[13] Phonapichat, Wongwanich, and Sujiva, "An Analysis of Elementary School Students' Difficulties in Mathematical Problem Solving", Procedia - Social and Behavioral Sciences, pp. 3169-3174, 2014.

[14] A. V. Borovik and Gardiner, "Mathematics Competitions Mathematical Abilities and Mathematical Skills", Mathematical Abilities and Mathematical Skills, p. 1, 2006.

[15] K. Nunokawa, "Mathematical Problem Solving and Learning Mathematics: What We expect Students to obtain", Mathematical Behavior, vol. 24, pp. 325-340, 2005. 